\title{
Política y políticas públicas
}

Eugenio Lahera P.

División de Desarrollo Social

NACIONES UNIDAS

C E P A L Santiago de Chile, agosto de 2004 
Ш

-

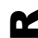

95

U

$\boldsymbol{\infty}$

políticas sociales

\section{olítica y políticas públicas}

Eugenio Lahera P.

División de Desarrollo Social

NACIONES UNIDAS 
Este documento fue preparado por Eugenio Lahera P., Consultor de la División de Desarrollo Social de la Comisión Económica para América Latina y el Caribe (CEPAL). El estudio forma parte del proyecto "Política y políticas públicas en los procesos de reforma en América Latina. "Similitudes y diversidades" (Proyecto FRA/02/073) que la CEPAL lleva a cabo con el apoyo del Gobierno de Francia.

Las opiniones expresadas en este documento, que no ha sido sometido a revisión editorial, son de exclusiva responsabilidad del autor y pueden no coincidir con las de la Organización.

Publicación de las Naciones Unidas

ISSN impreso 1564-4162

ISSN electrónico 1680-8983

ISBN: 92-1-322570-9

LC/L.2176-P

$N^{\circ}$ de venta: S.04.II.G.103

Copyright @ Naciones Unidas, agosto de 2004. Todos los derechos reservados

Impreso en Naciones Unidas, Santiago de Chile

La autorización para reproducir total o parcialmente esta obra debe solicitarse al Secretario de la Junta de Publicaciones, Sede de las Naciones Unidas, Nueva York, N. Y. 10017, Estados Unidos. Los Estados miembros y sus instituciones gubernamentales pueden reproducir esta obra sin autorización previa. Sólo se les solicita que mencionen la fuente e informen a las Naciones Unidas de tal reproducción. 


\section{Índice}

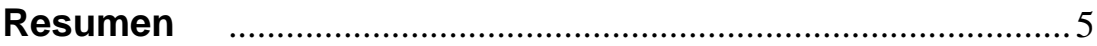

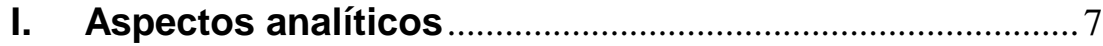

A. La política y políticas públicas; una relación recíproca ........ 7

B. ¿Qué es una buena política pública?...................................... 8

C. Etapas analíticas.................................................................. 10

II. La articulación de la política y las políticas ..................... 13

A. En el debate público ............................................................. 13

B. En el sistema político y las elecciones.................................. 14

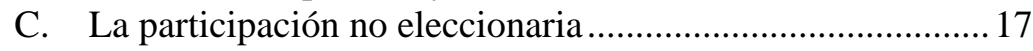

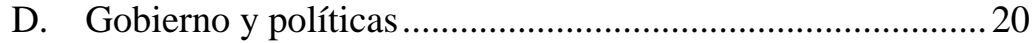

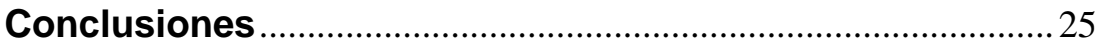

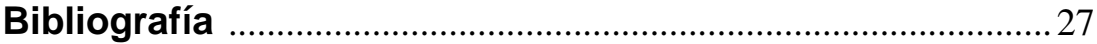

Serie Políticas Sociales: números publicados .......................29

\section{Índice de recuadros}

Recuadro 1 Carácterísticas de una política pública

de excelencia

Recuadro 2 Institutos de políticas públicas en América Latina ...... 17 

Las políticas públicas son un factor común de la política y de las decisiones del gobierno y de la oposición. Así, la política puede ser analizada como la búsqueda de establecer o de bloquear políticas públicas sobre determinados temas, o de influir en ellas. A su vez, parte fundamental del quehacer del gobierno se refiere al diseño, gestión y evaluación de las políticas públicas.

La búsqueda recíproca de la política y las políticas públicas representa una modernización de la esfera pública. En torno a políticas públicas se puede: acotar las discusiones políticas, diferenciar problemas y soluciones de manera específica, precisar las diferencias, vincular los temas a soluciones más amplias o secuenciales, plantearse esfuerzos compartidos, participar de manera específica.

Tal mejora requiere cambios en el sistema político y en el gobierno. Los partidos, los grupos sociales y las personas requieren interiorizarse el análisis de políticas públicas, sea que estén en el gobierno o en la oposición. Y la reforma del estado debe hacerse en torno a decisiones de políticas públicas. Primero la función, después el organigrama y sólo hasta que cambie la función; un gobierno con entradas y salidas. 



\section{Aspectos analíticos}

\section{A. La política y políticas públicas; una relación recíproca}

La política y las políticas públicas son entidades diferentes, pero que se influyen de manera recíproca. Ambas se buscan en la opacidad del sistema político.

Tanto la política como las políticas públicas tienen que ver con el poder social. Pero mientras la política es un concepto amplio, relativo al poder en general, las políticas públicas corresponden a soluciones específicas de cómo manejar los asuntos públicos. El idioma inglés recoge con claridad esta distinción entre politics y policies.

Las políticas públicas son un factor común de la política y de las decisiones del gobierno y de la oposición. Así, la política puede ser analizada como la búsqueda de establecer políticas públicas sobre determinados temas, o de influir en ellas. A su vez, parte fundamental del quehacer del gobierno se refiere al diseño, gestión y evaluación de las políticas públicas.

El objetivo de los políticos -tanto conservadores como radicales, idealistas o motivados por el interés propio- consiste en llegar a establecer políticas públicas de su preferencia, o bloquear aquellas que les resultan inconvenientes. En cualquiera alianza de gobierno, confunden su papel quienes se restringen a las tesis y no buscan su concreción en políticas.

Sobre las políticas públicas como la unidad de transacción de lo público véase Lahera, Eugenio (2003), Introducción a las Políticas Públicas, Colección Brevarios N538, Fondo de Cultura Económica. 
La política en su sentido más amplio tiende a conformar, tanto las propuestas de políticas públicas, como aquellas que se concretan. Quien quiere el gobierno, quiere políticas públicas.

Los gobiernos son instrumentos para la realización de políticas públicas Más que mirar al ordenamiento de las actividades del sector público, como dado por su organización, conviene mirarlo como un instrumento para la realización de las políticas públicas. Así como el logro principal de una empresa privada no es su organigrama, sino sus utilidades, lo importante en el gobierno son sus resultados, más que su estructura.

Por lo ya dicho, las políticas públicas resultan útiles para estudiar diversos aspectos de la política, tales como la discusión de la agenda pública por toda la sociedad, las elecciones entre candidatos y sus programas, las actividades del gobierno, las actividades de la oposición, los esfuerzos analíticos sobre estos temas

En torno a políticas públicas se puede:

$>$ acotar las discusiones políticas

$>$ diferenciar problemas y soluciones de manera específica

$>$ precisar las diferencias

$>$ vincular los temas a soluciones más amplias o secuenciales

$>$ plantearse esfuerzos compartidos

participar de manera específica.

Sin embargo, la política y las políticas públicas pueden no encontrarse al interior de un sistema político dado, o encontrarse de maneras muy diversas.

Por una parte, puede haber política sin propuestas de políticas públicas y entonces se tiene un sistema político concentrado en la distribución del poder entre los agentes políticos y sociales. La política sin políticas públicas es más demagógica, menos moderna.

Y, por la otra, puede haber políticas públicas que desconsideren la política, lo que debilita la gobernabilidad social. Las políticas públicas sin política tienen un problema de diseño.

Dicho de otro modo, dentro del gobierno no se puede olvidar la política y fuera del gobierno no se pueden olvidar las políticas públicas. Si no, se trata de actividades que emprenden una larga marcha por el desierto.

\section{B. ¿Qué es una buena política pública?}

Una política pública de excelencia corresponde a aquellos cursos de acción y flujos de información relacionados con un objetivo político definido en forma democrática; los que son desarrollados por el sector público y, frecuentemente, con la participación de la comunidad y el sector privado. Una política pública de calidad incluirá orientaciones o contenidos, instrumentos o mecanismos, definiciones o modificaciones institucionales, y la previsión de sus resultados.

Lo principal es la idea, el punto de vista, o el objetivo desde el cual plantear o analizar normas o disposiciones. Así es posible considerar a una norma o decisión o a varias (como el "programa" de Estados Unidos). También se ha usado la expresión "espacio de las políticas" para denotar un

Un caso de lo técnico buscando lo político puede verse en Rodríguez, Angela (2003), "De la Ficha CAS al Programa Chile Solidario", Tesis de pre-grado, Universidad de Los Lagos, Santiago. Un ejemplo de desencuentro puede verse en Medellín, Pedro (2003) "La política en los procesos de estructuración de las políticas públicas en Colombia", Documento de trabajo, Bogotá. 
conjunto de políticas tan interrelacionadas que no se pueden hacer descripciones o enunciados analíticos útiles de ellas sin tener en cuenta los demás elementos del conjunto.

Las políticas públicas de excelencia incluyen el aspecto político como su origen, objetivo, justificación o explicación pública. Si las políticas públicas no son enmarcadas en un amplio proceso de participación, ello puede sesgar a los actores públicos: los especialistas hacia la tecnocracia y los comunicadores o encuestólogos hacia al populismo inmediatista.

Una alternativa a la inclusión de las consideraciones políticas en las políticas públicas es la simple agregación de especialistas sobre algunos temas, o de soportes comunicacionales incluyendo el uso de cuñas y de encuestas- a las actividades tradicionales del gobierno.

Las políticas públicas de excelencia tienen características que favorecen una mejor discusión política; la principal es que son comparables formalmente:

\section{CARACTERÍSTICAS DE UNA POLITICA PÚBLICA DE EXCELENI \\ Recuadro 1
XCELENCIA}

1 Fundamentación amplia y no sólo específica (¿cuál es la idea?, ¿a dónde vamos?)

2 Estimación de costos y de alternativas de financiamiento

3 Factores para una evaluación de costo-beneficio social

4 Beneficio social marginal comparado con el de otras políticas (¿qué es prioritario?)

5 Consistencia interna y agregada (¿a qué se agrega?, o ¿qué inicia?)

6 De apoyos y críticas probables (políticas, corporativas, académicas)

7 Oportunidad política

8 Lugar en la secuencia de medidas pertinentes (¿qué es primero?, ¿qué condiciona qué?)

9 Claridad de objetivos

10 Funcionalidad de los instrumentos

11 Indicadores (costo unitario, economía, eficacia, eficiencia)

Fuente: CIPE (1996): Directory of Public Policy Institutes in Emerging Markets", Washington

Ellas son un marco, una estructura procesal que permite la especificación de las intenciones u objetivos que se desprenden de la agenda pública.

Aún la excelencia formal de las políticas públicas no es una garantía respecto de la corrección de sus contenidos sustantivos, los que pueden terminar siendo perfectamente equivocados o inconsistentes con los mecanismos propuestos o las soluciones institucionales definidas en la misma política.

De hecho, las políticas públicas habitualmente son un second best respecto de una política óptima en lo sustantivo, la que puede no existir. Con frecuencia la definición misma de las políticas públicas es el tema en disputa. En definitiva, es una cuestión de poder y de astucia quien "engloba" o incluye a quien.

En la filosofía política existen criterios para opinar al respecto:

- Según el óptimo de Pareto, el único criterio de mejoría social es que una situación alternativa sería mejor si el cambio aumentara la utilidad de algunos, sin disminuir la de

Majone, Giandomenico (1997), Evidencia, argumentación y persuasión en la formulación de políticas, México, Fondo de Cultura Económica. 
otros. Las críticas al utilitarismo se canalizaron, sin embargo, hacia el hecho que las comparaciones interpersonales de utilidad no tienen bases científicas.

Para Sen el bienestar no es la suma de las utilidades agregadas, sino las libertades de las que efectivamente dispone el individuo, utilizando los derechos y oportunidades que están a su alcance. No parece necesaria la existencia de comparaciones interpersonales muy refinadas para llegar a decisiones sociales. Una forma que estas comparaciones pueden tomar es la sensibilidad a las desigualdades en el bienestar y en las oportunidades.

- Por otra parte, es posible juzgar la situación de las personas en términos de su control sobre los bienes fundamentales, que corresponden a recursos de uso general, útiles para cualquiera, cualquiera sean sus objetivos. Una sociedad bien ordenada sería aquella en que los arreglos sociales se basan en un acuerdo que todos aprobarían, de tener la oportunidad; esta es la solución de Rawls.

Desde el punto de vista más instrumental, debe recordarse que las políticas públicas necesariamente representan algún tipo de simplificación de los problemas, característica de la que deriva su carácter operacional. Dicha simplificación puede tener un efecto negativo sobre una comprensión más amplia de los temas o problemas, e incluso puede sesgar la respectiva investigación académica. Más que despolitización de las decisiones gubernamentales lo que habría habido es una politización y degradación de un segmento considerable de las actividades de investigación.

Los temas económicos y sociales son tan dinámicos y relacionados y las actividades del gobierno que los afectan son tan numerosas e interconectadas, que la precisión en la interpretación de los desarrollos o en la predicción de los resultados de cualquier nueva intervención parece dudosa.

En todo caso, es necesario considerar también el peligro de la ideologización de los temas de la agenda pública, o su análisis en contextos no específicos o imposibles de convertir en políticas reales.

El concepto de políticas públicas incluye tanto temas de gobierno como de Estado. Estas últimas son, en realidad, políticas de más de un gobierno, lo que plantea una especificidad política. También es posible considerar como políticas de estado aquellas que involucran al conjunto de los poderes del estado en su diseño o ejecución.

\section{Etapas analíticas}

Desde un punto de vista analítico pueden distinguirse cuatro etapas en las políticas públicas y en cada uno existe una relación con la política: origen, diseño, gestión y evaluación de las políticas públicas. La articulación de la política y las políticas públicas puede ser mejorada en cada una de las etapas analíticas de estas últimas. Tal perfeccionamiento puede considerarse parte de la modernización del sistema político.

En Nueva Zelandia y otros países se ha intercalado otro "momento" analítico, aquel en que diversos contratos convierten el presupuesto de un acuerdo entre el gobierno y el parlamento sobre

\footnotetext{
Sobre este tema véase a Sen, Amartya (1998), "The Possibility of Social Choice", The American Economic Review, vol. 89, N³. Rawls, John (1971), A Theory of Justice. Traducido al español por el FCE, en 1979; la 3ra. edición es del año 2000, y Rawls, John (2000), Collected Papers, Harvard. Sobre estos temas puede verse, BeamDavid "If Public Ideas are so Important Now, Why are Policy Analysts so Depressed?", Journal of Policy Analysis and Management, Volumen 15, N³
} 
los montos a ser recaudados y gastados, en una declaración explícita de qué se hará con los recursos disponibles.

Las políticas rara vez se extinguen por completo; es más habitual que cambien o se combinen con otras. Se ha llegado a decir que las políticas públicas son inmortales. Sin embargo, existen políticas con aspectos temporales definidos, después de los cuales dejan de existir, por diseño (fade-out).

Cada parte del proceso tiene una naturaleza específica. Estas fases no necesariamente se dan en etapas causales y consecutivas, sino que en momentos analíticos de calidad y duración heterogéneas. La discusión social, la propuesta de políticas públicas y el proceso político tienen dinámicas distintas, si bien entre ellos existen efectos recíprocos, aunque asimétricos.

En algún momento de la dinámica de los temas públicos es posible la aceptación de una política, su rediseño o su extinción. Este momento requiere que coincidan la preocupación social, la existencia de una solución técnica y el apoyo político. Dado que ello es así, hay una ventaja en el uso temprano de las políticas públicas en el proceso que va de la agenda al programa y a las políticas.

La oportunidad para empujar propuestas propias es previsible, a veces, como en el caso de una renovación establecida de un programa. Otras veces ella se abre de manera impredecible. Quienes actúen en el terreno de lo público deben estar preparados, sus propuestas regalonas listas y sus problemas especiales bien documentados, a riesgo que la oportunidad los pase de largo.

Un requisito del desarrollo es que los procesos políticos y sociales sean gobernables, esto es, tengan un curso preestablecido para la articulación de propósitos y la resolución de conflictos; todos los conflictos, no sólo aquellos referidos a la macroeconomía. La gobernabilidad debe ser integrada. Ella debe referirse al conjunto de los sistemas sociales y no sólo a la organización productiva. Cuando la gobernabilidad es sesgada o parcial, tiende a ser inestable, como ha sucedido con aquella que sólo busca complementar el Consenso de Washington.

La gobernabilidad puede asegurarse de modo autoritario, por lo menos por un tiempo, pero es probable que lo sea de modo excluyente e inestable. La democracia, en cambio, es el sistema que posibilita una gobernabilidad incluyente y estable. Lo segundo, ya que por definición este sistema permite cambiar a los gobernantes sin crisis mayores.

Un modo populista y conciliador de hacer política privilegia la viabilidad política por sobre la eficacia. Los enfoques neoliberales, por el contrario, han privilegiado la eficacia económica por sobre la viabilidad política y por eso muchas veces se han combinado bien con autoritarismos. Lo importante es que hay maneras de hacerlo en democracia y con eficiencia, mediante la adecuada utilización de las políticas públicas.

Es indispensable percibir las limitaciones reales de este ciclo en la realidad. En cada etapa del ciclo de las políticas públicas existe la posibilidad de fugas o discrepancias entre los aspectos

(1998), “ (1976), “¿C Véase una crítica al respecto en , . (1993), Lahera, Eugenio y Cabezas, Mabel (2000), “Governance and institutional Development of the chilean Economy", Journal of International Development, 12. 1087-1109.

Un enfoque que exagera la desarticulación de las facetas del proceso es el llamado modelo "cesto de la basura", de Michael Cohen, James March y Johan Olsen (1972), "A Garbage Can Model of organizacional Choice", Administrative Science Quarterly 17, marzo. A través de las estructuras de organización y decisión fluyen cuatro corrientes: problemas, soluciones, participantes y oportunidades de elección. Cada una de estas corrientes tiene una vida propia, en su mayor parte no relacionada con las demás. Este tipo de organización es una colección de selecciones buscando problemas, temas y sentimientos buscando situaciones de decisión en las cuales puedan ser planteados, soluciones buscando temas para los que puedan ser la respuesta, y tomadores de decisiones buscando trabajo. Una oportunidad de seleccionar una política es, por lo tanto, un cesto de basura en el que se botan diversos tipos de problemas y soluciones. Con este enfoque los problemas y soluciones tienen un status igual como corrientes separadas en el sistema y la popularidad de una solución determinada a menudo afecta los problemas que están siendo considerados. En Kingdon, John (1995), Agendas, Alternatives, and Public Policies, Harper Collins, Nueva York. 
analíticos del enfoque y los aspectos positivos a los que se aplica. Esto puede verse con mayor detalle.

No toda idea entra a la agenda. No todos los temas de la agenda se convierten en programas. La permanente posibilidad de pensar los arreglos sociales de otro modo, imposibilita que se complete el paso de la agenda al programa. En el paso de la discusión pública al programa y de éste a la agenda siempre hay fugas y no se logra captar toda la riqueza de la discusión.

- El diseño puede ser defectuoso porque no considere aspectos institucionales o porque no incluya modalidades de evaluación de las políticas. Sus orientaciones pueden ser meras declaraciones, sin apoyo financiero o de personal.

- La gestión de las políticas es habitualmente imperfecta. Cuando no se mejora la política sustantiva de manera integrada, es posible que se gasten más recursos sin que los resultados mejoren, o lo hagan de manera menos que proporcional.

- La gestión puede ser discordante con las políticas, incluso para enriquecerlas o adaptarlas. Buena parte de los equívocos con los funcionarios públicos civiles vienen de políticas mal diseñadas en cuanto a su puesta en práctica, o con correcciones laterales, en vez de una modificación integrada. Mientras no se encaren las reformas sustantivas, de modo integral los funcionarios públicos considerarán que los cambios son para perjudicarlos.

- En la evaluación las fugas pueden ser aún peores. Ella puede simplemente no existir, con lo que la pérdida de eficiencia y efectividad potencial es enorme. O puede haber una evaluación parcial o ad hoc, para resultar conforme a una opción elegida de antemano. O, todavía, pueden evaluarse políticas de menor trascendencia, en vez de las más importantes y complejas. 


\section{La articulación de la política y las políticas}

\section{A. En el debate público} pública?

¿Cómo se puede pasar del mundo de las ideas a la acción

Todos podemos generar, refinar o combinar ideas, si bien algunas ideas o sistemas de ideas son más potentes que otras. Muchas ideas tienen consecuencias sociales pueden ingresar al conjunto de los temas que una sociedad discute.

Toda sociedad tiene un debate sobre si misma. La riqueza de una sociedad se mide por su discusión pública, así como por su capacidad de transformarse a partir de ella. De allí que la democracia debe educar a sus ciudadanos en su habilidad de plantearse públicamente.

¿Qué ideas son ganadoras en la discusión social? Es indudable que algunas personas y corporaciones tienen mayor capacidad de incluir, jerarquizar y excluir temas en la discusión social. Así, la agenda pública se constituye como un juego de poder en donde se construyen legitimidades e ilegitimidades y el ordenamiento de unos valores a otros, aunque sea de manera implícita.

Que los intereses particulares compitan y confluyan en la formación de las políticas públicas es de la esencia de la democracia. Pero, como en todo juego, debe haber reglas comunes para quienes participan. Y el lobby, la corrupción y la falta de transparencia en el financiamiento de la política son reglas de la desigualdad. 
¿Qué factores condicionan la riqueza de la discusión social? Entre ellos destaca el acceso desigual a la educación y al Internet, así como la falta de representatividad de los medios de comunicación y el lobby indirecto, mediante la movilización de la opinión pública. Todos ellos pueden inhibir o sesgar la discusión social.

James Madison, uno de los padres del constitucionalismo en Estados Unidos pensaba que cuando distintos grupos de interés o "facciones" tratan de influir en adhesiones del gobierno, es probable que ninguno de ellos prevalezca y el resultado sea la búsqueda del interés general o agregado. Pero es evidente que dichos sesgos también pueden agregarse, multiplicando así la distorsión de una voluntad ciudadana.

Las ventanas de oportunidad para los problemas en general y para sus aspectos políticos están relacionadas. Cuando se abre una ventana de oportunidad porque un problema gana importancia, las soluciones planteadas tienen más éxito si también obtienen aceptación política. Al revés la falta de aceptación política las hace menos viable. La definición de la agenda pública es definida y redefinida también según la dinámica de las fuerzas políticas.

También son importantes la factibilidad técnica y una previsión de costos tolerables.

La agenda pública incluye muchos puntos de vista, incluso contradictorios, los que podrían no tener cabida en el mismo programa. También porque hay sectores sociales subrepresentados, mientras otros tienen una capacidad desproporcionada de representación de sus propios intereses. La participación es un bien que se distribuye de manera muy heterogénea.

La discusión social cambia. En el mediano plazo, los temas debatidos tienen diversos grados de concreción: algunos se realizan, otros sólo parcialmente. Algunos son superados u olvidados.

\section{B. En el sistema político y las elecciones}

La capacidad de definir un programa en lo social, político y económico es determinante de la estabilidad y del carácter reformista de la democracia, así como la precisión del respectivo pacto fiscal.

Los programas de estabilización y de reforma, y los consiguientes cambios institucionales, requieren un apoyo sostenido en sus diversas fases; también las propuestas para anticipar o superar situaciones críticas.

Por otra parte, en relación a los bienes y servicios públicos esenciales y otras de acceso universal se requiere una decisión social o colectiva sobre los niveles de provisión y respecto de si y cómo asegurar el acceso igualitario a la salud, educación y bienestar, en general. Por supuesto, la provisión de estos bienes puede ser privada o mixta.

La línea de menor resistencia siempre será la suma de gestiones e intereses, que habitualmente resultará en programas perversos. De allí que se requieren esfuerzos permanentes para analizar los argumentos en conjunto y plantear opciones jerarquizadas de políticas que sean consistentes, financiables y que cuenten con apoyo político sostenido.

Habitualmente un programa es una selección de temas y propuestas hecha por el sistema político, principalmente por los partidos. Esta selección puede ser hecha con mayor o menor arte en cuanto a su coherencia, secuencia, financiamiento y proyección del apoyo político.

La posibilidad de articular un programa es terreno privativo de lo político, porque los números no hablan por sí solos y las programaciones no pueden ser autoevidentes. Por otra parte es poco realista eliminar las políticas entregando a los filósofos la determinación de la amplitud de la libertad individual y la distribución de los bienes sociales y a los jueces su aplicación. 
La política es "la esfera de la decisión social", particularmente en democracia.

Las elecciones son muy importantes no sólo por la posibilidad de algún tipo de mandato desde la ciudadanía, sino también porque pueden variar las personas en posiciones de autoridad.

Sin embargo, los partidos políticos subutilizan a sus cuadros técnicos, pese a la excelencia que éstos puedan demostrar después en el gobierno. En las propuestas que los partidos realizan suelen faltar una o más de las condiciones deseables de una política pública.

El sesgo particularista ya no sólo se da en el origen de las políticas, sino también en la conceptualización y selección de ellas; de hecho, algunas ni siquiera tienen la oportunidad de ser rechazadas por la ciudadanía, lo que puede reforzado por sistemas electorales poco representativos.

En la discusión política habitualmente predomina la retórica en torno a unos pocos temas de alta visibilidad, no siempre de gran interés público. Los partidos políticos, de gobierno y de oposición, rara vez examinan con profundidad las actividades de los gobiernos; los institutos de políticas públicas lo hacen con mayor frecuencia, pero su relación con los partidos, el gobierno y el Congreso es poco fluida.

Los políticos, actuando en un marco institucional adecuado, pueden administrar las restricciones del Teorema de las Imposibilidades de Arrow en la realidad. ${ }^{13}$ Los programas representan en la práctica una posibilidad de articulación social de preferencias individuales o de grupos que de otro modo podrían ser eternamente inconsistentes.

Pese a los intentos de agregar las racionalidades individuales en una racionalidad colectiva, siempre persistirá una brecha entre ambas. Si bien es posible que existan divisiones unívocas y consistentes del electorado en torno a algunos temas, es claro que esta no es la situación general.

Por otra parte, Anthony Downs señala que los partidos plantean políticas para ganar las elecciones, más que ganan elecciones para plantear políticas. En la práctica tiende a darse que las políticas convergen hacia el centro de modo que coinciden la media, la moda, y el promedio.

La mediana correspondiente al resultado es independiente de la distribución de las preferencias; los votantes que se ubican entre la posición del candidato y un extremo hacia el otro candidato, son "atrapados" a votar por él. El único equilibrio político posible corresponde a que los dos partidos propongan lo mismo, evitando una respuesta del adversario. Un supuesto de este enfoque es que la opinión política corresponde a una sola dimensión tal como liberal -conservador o derecha- izquierda.

Una condición de éxito al respecto es la efectiva articulación de la voluntad general: ella requiere la formulación de programas claros y consistentes de políticas públicas, de alta calidad técnica y política y respecto de los cuales se logre reunir el máximo de apoyo político y se asegure la gestión más eficiente y eficaz posible.

A partir de esta discusión social, son privilegiadas algunas propuestas de política y se conforman los programas políticos. Aquí se agregan a los anteriores factores de inhibición o de sesgo de las políticas públicas el que los partidos y candidatos políticos tengan acceso a niveles de

, (1966), w , (1951), ,” ,”, Washington, DC. , John (1995), Agendas, Alternatives, and Public Policies, Carper Collins, Nueva York. Erik (1966), R , $L$, , Rosa (1987, Sobre un caso de "overshooting" del enfoque del consenso véase en Eugenio Lahera y Mabel Cabezas, Op. cit. 
financiamiento muy disímiles, de cero a más de lo necesario, incluyendo el mal uso de la propaganda de los gobiernos.

Para ello, debería reformarse el estatuto de los partidos políticos para que puedan ser mejores canales de las opiniones ciudadanas, incluyendo formalidades precisas en la elección de candidatos y de directivas, así como modalidades de vida partidaria.

Debería haber financiamiento público para la información programática de los partidos, además de hacer transparente el gasto político de origen privado. Se trata de un mercado imperfectamente competitivo, en el que se deben incurrir grandes costos de ingreso.

Los sistemas electorales, así como las normas de agregación, ejercen influencia sobre la naturaleza de la coordinación, la credibilidad y los problemas de agencia que los sistemas fiscales deben encarar afectando el número de actores.

Para los mismos resultados electorales, algunas normas de agregación -como el sistema electoral británico- pueden dar lugar a grandes mayorías, mientras que otras -como los sistemas de representación proporcional- pueden conducir a numerosos pequeños partidos que deben gobernar a través de coaliciones.

Para los mismos resultados electorales, un sistema en el que las inversiones sobre caminos son decididas por los gobiernos elegidos localmente podría conducir a una asignación de recursos muy diferente de un sistema en el cual las decisiones se adoptan en un congreso nacional.

El sistema político no se familiariza bien todavía con esta nueva situación, en donde las políticas públicas han ido ocupando terreno antes privativo de la retórica.

La estabilidad de la agenda del sistema político se debe a lo que podemos llamar sus anclas. Cuando existe una menor estructuración, la agenda puede cambiar de manera más rápida. La fragmentación del sistema política afecta la estabilidad de su agenda.

La plataforma o programa de los partidos políticos en general no constituye una guía suficiente para las políticas que se seguirán en el gobierno, si bien en ellos se introducen o eliminan temas y planteamientos novedosos, lo que puede dar origen a modificaciones de agenda y en las orientaciones de políticas.

Fuera del gobierno y, con frecuencia, también de los partidos, los institutos de políticas públicas habitualmente reúnen a técnicos y políticos que encuadran sus propuestas de políticas en determinados marcos analíticos, e ideológicos. Estos institutos parecen cubrir un espacio descuidado por los partidos políticos; sólo el tiempo dirá sí para detrimento de dichas organizaciones, o como una respuesta funcional a una demanda.

Los Institutos en general se plantean en torno al diseño -si bien no exclusivamente- de las políticas públicas, tanto para apoyar determinados aspectos como para bloquear otros.

Es habitual, en este sentido, que se relacionen con los partidos políticos y el Poder Legislativo, sin perjuicio de llegar también a públicos corporativos o especializados.

Recuadro 2

INSTITUTOS DE POLÍTICAS PÚBLICAS EN AMÉRICA LATINA

Destacan, la Fundación de Investigación Latinoamericana (FIEL) y el Instituto de Estudios Económicos de Argentina y América Latina, ligado a la Fundación Mediterránea, en Argentina; el Instituto Atlántico y el Instituto Liberal de Río de Janeiro, en Brasil; el Instituto de Libertad y Desarrollo y el Centro de Estudios Públicos en Chile; el Centro para la Orientación Económica en República Dominicana; el Centro de Investigación Económica Nacional, de Guatemala; el Instituto APOYO y el Instituto de la Economía de Libre Mercado, en Perú; el Centro para el Estudio de la realidad Económica y Social (CERES) en Uruguay; y el Centro para la Diseminación de Información Económica, en Venezuela. 
Fuente: CIPE (1996): Directory of Public Policy Institutes in Emerging Markets”, Washington.

\section{La participación no eleccionaria}

Pero la comunidad puede influir políticamente en la determinación de las políticas públicas de manera más continuada que a través de los partidos políticos y las elecciones.

A nivel de la sociedad civil no se puede esperar que los individuos formen grandes asociaciones voluntarias para fomentar temas de interés público, a menos que existan condiciones especiales para ello.

Los procesos de concertación suponen la existencia de una serie de factores, tales como la participación de los agentes sociales en la elaboración y toma de decisiones de políticas públicas; su responsabilidad respecto a normas de la negociación y su voluntad de cooperación.

Para que la concertación sea percibida como un ejercicio legítimo y conveniente, ella debe atender a los diversos intereses y partes. Por otra parte, el consenso representa una observación en un continuo. Es poco frecuente y poco duradero, salvo excepciones.

Los acuerdos de concertación deben ser institucionalmente procesados, evitando reducir a las instituciones democráticas al papel de instancias de mera ratificación de lo acordado.

Junto al impulso de los acuerdos, se requiere generar escenarios que permitan encauzar y negociar conflictos e intereses contradictorios; de otro modo el consenso se puede convertir en su propio enemigo, al intentar reemplazar la dinámica social por negociaciones cupulares.

En el análisis político suele asumirse muy estrictamente una racionalidad de las expectativas. Para evaluar sus ganancias con un cambio de política los agentes deben entender completamente como los afectaría tal cambio, incluyendo sus efectos generales de equilibrio.

Mediante la participación de personas o grupos ellos pueden influir, hacerse presentes, en la agenda pública y también en la formulación, ejecución y evaluación de las políticas públicas.

Esto puede favorecer el tratamiento de los temas públicos, al haber menos temas "no atribuibles" a algún grupo social

- Ella permite una distribución más equitativa del poder y una mayor visibilidad de los problemas sociales; con frecuencia puede ser la base de capacidades determinadas en los grupos beneficiarios, además de aumentar la efectividad y la eficacia de las políticas.

- La participación es un modo privilegiado en que los ciudadanos y las organizaciones que los agrupan puedan hacer valer sus opiniones en el período que va entre un acto eleccionario y otro.

- Ella representa un complemento indispensable de la burocratización de los actos gubernativos, otorga mayor transparencia al sistema político y agiliza la consideración de los problemas sociales más relevantes; es también fundamental si se desea transferir más poder a la ciudadanía o a los potenciales participantes en otros ámbitos.

\footnotetext{
," Un caso interesante puede verse en Frohmann, Alicia 2003 "Consultas con la sociedad civil sobre negociaciones comerciales: el caso de Chile", Ponencia en Seminario, BID, Milán.

Con este argumento, Coase favorece la atribución completa de derechos de propiedad.

, . (1992), (1996),.. çç ， Kingdon, John W. (1995) ,Op. cit.
} 
- La participación es también un modo privilegiado de expresar la participación social; de hacer presente a los diferentes grupos, tanto en sus demandas específicas, como en su visión del mundo. Es una manera en la que la sociedad se reconoce a sí misma.

Desde otro punto de vista, la participación es una avenida de doble tránsito, en la que puede haber problemas de ida y de vuelta. Por una parte, con ella se abren posibilidades de la manipulación por quien la organiza o conforma. Por la otra, también puede ser ocasión de una avalancha, debido a un potencial efecto multiplicador de las demandas.

En cuanto al número de personas que participa, parece claro que un medio potente de lograr un aumento de la participación es el desarrollo sostenido de los esfuerzos de descentralización, ya que con ésta se puede lograr una dimensión más adecuada para la interacción entre las autoridades y los diversos grupos sociales.

La cercanía entre las autoridades y las comunidades ofrece una mejor capacidad de respuesta y otorga más transparencia al suministro local de bienes y servicios, así como un claro incentivo a la introducción de innovaciones a la gestión fiscal local y a la mayor responsabilidad de la población en la esfera política.

En cuanto a la complejidad de los temas respecto de los cuales puede darse la participación, cabe preguntarse si ella tiene un límite natural. Sin duda existen asuntos extremadamente complejos, cuya resolución se vería demorada en caso de requerir una participación detallada. Por otra parte, tanto la voluntad política de hacer realidad la participación como la tecnología de comunicaciones, hacen retroceder dicho límite cada día. Forma parte del desarrollo el que la opinión pública tenga una capacidad creciente de entender y opinar sobre temas complejos.

Según los temas, la participación puede alcanzar diversos niveles de intensidad, incluyendo el compartir información, realización de consultas, participación en las decisiones y/o en la implementación de las políticas.

La organización y la capacitación son requisitos de existencia para la participación de numerosos grupos sociales. También es necesario un ordenamiento criterioso de las modalidades de participación y su adecuada jerarquía. Diversas organizaciones sociales tradicionales han perdido vigencia; por otra parte, nuevas situaciones en las que la participación sería posible, todavía no encuentran una expresión institucional adecuada.

La información es un antecedente indispensable de toda participación. Se trata de información básica, abierta y no predigerida, a la que se pueda acceder libremente. De este modo puede generarse opinión pública y no sólo preconformarla mediante encuestas. La tecnología de comunicaciones facilita una interacción significativa, incluso con grupos mayores. Sin embargo, cuando la sociedad civil tiene fuertes rasgos tradicionales, incluyendo el autoritarismo, ello dificulta la ocupación de los espacios naturalmente llamados a la participación.

Las comunidades de políticas son aquellos grupos de especialistas que comparten una determinada área temática y que tienden a algún grado de relación entre ellos. Es habitual, sin embargo, que predominen en ella los consultores de empresas.

Por otra parte, y pese a las expectativas a su respecto, el internet no parece haber modificado de manera importante la política. En lo principal parece haber reforzado la participación de los diversos sectores con acceso a la tecnología.

Sin embargo, es evidente que en internet ha removido el principal obstáculo a la democracia directa, cual es la dificultad física de distribuir información, participar en debates y obtener las votaciones. La perspectiva de crecientes cursos de democracia directa plantearán la necesidad de nuevas reglas, procedimientos y desarrollos institucionales. 
El acceso a la información se seguirá expandiendo, lo que puede favorecer una mayor participación. Desde otro punto de vista, es posible que internet se desarrolle en una herramienta de control social.

La participación puede mejorar la gestión pública de diversos modos:

- la información acerca de las necesidades, prioridades y capacidades de las comunidades o sectores involucrados puede incrementarse;

- los programas pueden ser mejor adaptados a las necesidades locales, lo que favorece un mejor uso de los recursos;

- la entrega de los servicios puede ser de mejor calidad y atender mejor a la demanda;

- permite movilizar recursos locales;

- puede mejorar la utilización y la mantención de las instalaciones y servicios gubernamentales.

Sus inconvenientes incluyen: mayores costos de transacción iniciales; aumento de las expectativas racionales; eventual captura de recursos del desarrollo por élites locales; y la posibilidad de sustituir, en vez de complementar, el conocimiento técnico con la información local.

La producción no lucrativa por la sociedad de bienes o servicios públicos no exclusivos del estado, requiere del fortalecimiento de las organizaciones sociales que puedan llevarlo a cabo.

Es de particular importancia reconocer la significación de la "voz" en casos en los que no hay "salida" factible de los usuarios de determinados servicios públicos; en casos de monopolios naturales, por ejemplo.

La participación no sólo debe aumentar los canales de expresión a la sociedad civil, sino también hacerla responsable de sus demandas y preocupaciones.

El aumento de la participación ciudadana requiere también mayores posibilidades de resistencia legal respecto de las decisiones de gobierno.

La capacitación sobre gestión a líderes elegidos por sus grupos comunitarios puede contribuir a precisar responsabilidades y facilitar la rendición de cuentas. Por otra parte, la participación de los usuarios en relación a los servicios aumenta la accountability de los funcionarios.

La opinión pública puede afectar más la agenda que las políticas. Los actores visibles tienden a afectar más la agenda, mientras quienes influyen más en las políticas son menos visibles. Otra de las limitaciones para que la opinión pública afecte el diseño de las políticas es que muchas esferas importantes son casi invisibles para el público en general.

En los países cuyos medios de comunicación representan un arco considerable de las posiciones sobre la agenda, es habitual que dichos medios no tengan una influencia decisiva en la conformación de ésta. Sin embargo, en los países donde los medios de comunicación representan opciones pequeñas de la agenda, su influencia tiende a ser mayor. Contribuye a tal resultado el que la relativa falta de competencia permite alargar los tiempos de atención sobre temas determinados.

Los medios de comunicación se han erigido en el espacio fundamental de la política, aquel en el que se forman las opiniones y las decisiones de los ciudadanos. Esto no quiere decir que los medios de comunicación tengan el poder, pero en ellos se juega el poder, por lo cual la política tiene que adaptarse a un lenguaje mediático que tiene tres reglas: simplificación del mensaje, personalización de la política, predominancia de los mensajes negativos de desprestigio del adversario sobre los positivos que tienen poca credibilidad. 
Todo ello conduce a la política del escándalo como arma fundamental de acceder al poder, por eliminación del contrario.

En la sociedad civil sólo un número pequeño, aunque creciente, de entidades realiza planteos integrados de políticas públicas. Las organizaciones de la comunidad tienen poco acceso a la información, lo que sesga la participación.

Por otra parte, las políticas públicas todavía no reciben la atención que merecen a nivel académico y de los medios de comunicación.

La discusión habitualmente se ha caracterizado por el predominio de la retórica y la falta de precisión, mientras el conjunto de políticas reales (de mayor o menor calidad técnica) resulta privativo de los gobernantes y estudiosos, o aparece de modo desdibujado en la prensa.

Pareciera, sin embargo que los ejercicios retóricos tienden a concentrarse en unos pocos temas de alta visibilidad, aunque no siempre de gran interés para la gente.

\section{Gobierno y políticas}

Los límites, los tiempos y las técnicas que separaban a las actividades propias del gobierno y aquellas correspondientes a las campañas políticas se han hecho más borrosos.

Las campañas buscan persuadir y el gobierno hacer, pero esta distinción es más o menos aguda, según el sistema político de cada país y la mayoría que el gobierno tenga en el parlamento. Los plazos en las campañas son indefinidos, todo parece posible en cualquier minuto. No es así en el gobierno, donde las opciones y las secuencias son muy importantes.

Como resultado, el tiempo de la política parece haberse hecho permanente lo que con frecuencia resulta en un descrédito de la actividad.

Las campañas políticas tienen por objeto obtener votos o porcentajes de aprobación en las encuestas, objetivo compartido por los gobiernos. Por otra parte, las campañas no requieren ser precisas o detalladas, sino que basarse en frases simplificadoras.

Las campañas se basan en la utilización de encuestas como proxy de votaciones menos espaciadas; y en las comunicaciones basadas en una frase por día, los seudoeventos y el privilegio de las imágenes televisivas.

El gobierno tendrá habitualmente más material con el que plantearse frente al público y tendrá logros que exhibir, mientras los partidos siguen en el limbo hasta las próximas elecciones. Esta tendencia puede contribuir a la declinación de los partidos políticos.

Se ha planteado la existencia de la "paradoja de la determinación", conforme a la cual las grandes condiciones de equilibrio político-económico, cualquiera que ellas sean, predeterminan lo que sucederá. Sin embargo, se comete un error cuando se aconsejan políticas públicas sobre la base de una visión estrecha de su factibilidad. No hay ninguna diferencia esencial entre las restricciones técnicas, económicas, políticas, institucionales o de cualquier otra clase: todas limitan la libertad de elección del gobernante, y su violación lleva siempre consigo una sanción.

Los gobiernos deben especificar los programas en políticas públicas para su período. Esta determinación es un modo efectivo para no darle a mucha gente lo que quiere. Lo habitual es que

\footnotetext{
Una mirada muy crítica de este hecho puede encontrarse en Heclo, Hugo (2000), "Campaigning and Governing: a Conspectus", en Norman Omstein y Thomas Mann, editors, The Permanente Campaign and its future, Washington, American Enterprise Institute The Brookings Institution.

Majone, Giandomenico (1997), Op. cit.
} 
no haya políticas públicas óptimas, sino un rango de soluciones posibles. No hay garantía de escoger la mejor política pública. Pero es un deber de los gobiernos elegir cursos de acción.

Las nuevas políticas públicas corresponden a una selección de temas y objetivos del programa de gobierno. Sin embargo, ellas se vienen a sumar a todas las políticas en efecto.

Es conveniente distinguir entre el programa público y la agenda del gobierno, a veces porque la demagogia infló el programa $y$, en todo caso, porque se aspira a elegir secuencias óptimas, efectos de cascada, momentos políticos y económicos.

Una actividad central de un grupo de interés es lograr incorporar sus propias alternativas a temas de agenda que otros han hecho prominentes. Así se afectan las políticas consideradas, incluso si no se afecta la respectiva agenda.

Los gobiernos requieren coordinar sus políticas públicas con los partidos políticos. Los partidos políticos deben ser capaces de organizarse para las elecciones, pero también de gobernar; para ello, sería conveniente fortalecer los institutos de estudio ligados a ellos e insistir en la incorporación de personas con capacidad técnica y científica para diseñar las propuestas de políticas públicas.

Para el diseño de las más diversas políticas públicas, el Poder Legislativo tiene un papel de gran importancia. Allí es más frecuente la búsqueda de acuerdos basadas en la negociación. En este último caso las coaliciones se construyen en un intercambio de concesiones, a veces se negocia, mas que por la virtud de una política porque quedarse afuera sería peor.

Es conveniente formalizar diversos mecanismos de información y consulta entre el gobierno y el Parlamento, de modo de mantener oportuna y debidamente informadas a las bancadas sobre las iniciativas del Ejecutivo. Ellos pueden incluir reuniones semanales de ministros del área política con los presidentes de los partidos y los jefes de las bancadas, la constitución de comisiones bipartitas Poder Ejecutivo-bancadas parlamentarias y una fluida red de información con los partidos de oposición.

Cuando no ha llegado el momento de algún tema quienes hacen planteamientos al respecto tienden a adherir a posiciones extremas. Pero cuando el tema tiene una posibilidad seria de acción legislativa o gubernamental quienes lo plantean adquieren mayor flexibilidad. Se ha planteado la existencia de un ciclo de atención a los temas, el que llama a una acción rápida cuando se presenta la oportunidad, especialmente en los aspectos financieros y los costos sociales de la acción propuesta.

La adecuada conjunción de los aspectos técnicos y políticos caracteriza a las políticas públicas de excelencia, ¿cómo lograrla? Una posibilidad es la de combinar una sucesión de estudios de opinión pública con el consecuente acomodo de las políticas públicas a ser planteadas.

Entre las habilidades de un técnico-político destacan la capacidad de presentación y análisis, incluyendo el manejo de analogías y el conocimiento acabado de los aspectos institucionales, así como del sentido político de la oportunidad. En este sentido se valora especialmente el ser capaz de

Kingdon, John (1995) Op. cit.

(1996,. Pizarro, (1995), F (1993), Dral, $\quad$ Downs, Anthony, (1972), "Up and Down with Ecology-The 'Isue-Attention Cycle".

The Public Interest 28 Pag.38-50. 
poner los temas en una perspectiva más amplia, que permita formarse una opinión que considera, pero trasciende, las minucias específicas.

El acabado manejo de la información y del conocimiento necesario para plantear alternativas no es suficiente, ya que se requiere seleccionar lo relevante y destacar los resultados y costos previsibles.

Es fundamental adquirir habilidad y precisión en el lenguaje escrito, saber razonar por analogía, conocer detalles institucionales y aspectos legales de los diversos procesos. Es también importante ser capaz de anticipar cómo serán percibidas las políticas y plantear su defensa en términos más amplios, ideológicos o filosóficos.

Además es necesario poder establecer supuestos simplificadores y reducir la complejidad de los temas a ser tratados. Traducir los diseños de política en actitudes del mundo real, en un medio de gestión caracterizado por un escrutinio intenso y por reglas a veces difíciles o absurdas; también la capacidad de experimentar con soluciones novedosas.

En un sistema de gobierno que se guía por la deliberación pública, el análisis -aun el análisis profesional- tiene menos que ver con las técnicas formales de solución de problemas que con el proceso de argumentación.

Parte esencial de la tarea del analista consiste en explicar y defender un plan de acción razonable cuando el óptimo teórico se desconoce o es prácticamente inalcanzable. El analista de políticas es un productor de argumentos de las políticas, más semejante a un abogado -un especialista en argumentos legales- que a un ingeniero o un científico. Sus capacidades básicas no son algorítmicas, sino argumentativas: para examinar con espíritu crítico los supuestos, para producir y evaluar pruebas, para conservar muchos hilos en la mano, para buscar un argumento en muchas fuentes dispares, para comunicarse efectivamente.

Vale la pena considerar el tema de la calidad de las asesorías sobre políticas públicas. En el caso de Nueva Zelandia se han establecidos estándares de calidad al respecto los que incluyen: claridad de propósitos, lógica intrínseca, precisión, adecuado rango de opciones, realización de las consultas necesarias, carácter práctico de su implementación, presentación efectiva.

Los gobernantes necesitan el análisis retrospectivo (posterior a la decisión) por lo menos tanto como del prospectivo (anterior a la decisión), y probablemente más.

Algunas políticas públicas son más importantes que otras. Y está en la naturaleza del buen gobierno que su acción se ordene principalmente en torno a orientaciones y políticas estratégicas. Son políticas estratégicas aquellas que prefiguran el legado del gobierno. Ellas deben dar los principales criterios de evaluación de la gestión propia y permitir ordenar a los partidos que apoyan al gobierno.

Se requiere una visión estratégica de mediano plazo que conjugue adecuadamente la dimensión política y la técnica en las políticas públicas. Para ello conviene institucionalizar una "hoja de ruta" para la gestión del gobierno, que se evalúe y actualice periódicamente. La función de análisis prospectivo debería convertirse en una rutina formal en la gestión del Poder Ejecutivo.

\footnotetext{
Nelson, (1987), Gobierno de (1992),“”, , J.M. (168), "An Economist's Approach to "Scientific Politics”, en M. Parsons, (ed), Perspective in the Study of Politics, Rand Mc Nally, Chicago. ， （1995), Otawa, octubre （1995), (1995), Ottawa, octubre Lahera, Eugenio (1992), "Un sector público con entrada y salida”, El Diario, Santiago de Chile, 29 de mayo.
} 
Las encuestas miden resultados, más que generarlos; no debe confundirse al termómetro con la temperatura. Las preguntas importantes son: ¿qué puede ocurrir?; ¿qué puede hacer el gobierno?; ¿qué hará el gobierno?; y ¿cómo lo hará? ¿Qué se deduce de las proyecciones?

No se puede entregar asesoría sobre políticas públicas suponiendo que la autoridad es un déspota benevolente, sino considerando la estructura donde se toman las decisiones de política pública.

El lobby es una actividad con la que se busca influir en la elaboración, gestión o interpretación de políticas públicas para privilegiar unos intereses en perjuicio de otros. Conviene regular y no pretender ignorar a los grupos de presión, así como a las actividades de lobby.

Existen diversas clases de lobby: el directo se ejerce sobre los poderes públicos, sean ellos el Poder Ejecutivo o el Congreso; el indirecto se ejerce a través de la movilización de la opinión pública, por ejemplo mediante el envío de cartas o mensajes a parlamentarios o autoridades. El lobby puede ser ejercido directamente por el grupo de presión o empresa, o por profesionales de la actividad, independientes o integrados en una agencia.

Los institutos de políticas públicas habitualmente realizan diversas actividades de lobby.

Convendría inhabilitar a ex funcionarios de alto nivel y ex parlamentarios para ejercer actividades de lobby, por ejemplo por dos años.

En la gestión pública de las políticas, o con ocasión de ésta, que puede aparecer la corrupción, habitualmente como actividad conjunta pública y privada, para un beneficio particular.

La evaluación de las políticas es una actividad casi inexistente en América Latina y que llega poco a la opinión pública. En cambio, dicha opinión pública suele ser bombardeada con resultados parciales o estudios ad hoc para sesgarla de manera favorable hacia intereses particulares.

Puede notarse que hay actores que forman parte del elenco tanto en la discusión social, como en la conceptualización, diseño y gestión de las políticas públicas. Se trata de los institutos de políticas públicas los que, en buena medida, han venido a reemplazar el papel propositivo de los partidos políticos. Ellos también suelen tener financiamientos muy disímiles, a veces con subsidios públicos en forma de reducciones impositivas.

Las personas y organizaciones que tienen un interés en la política o programa evaluado y en las conclusiones de la evaluación (stakeholders) deben poder conocer y utilizar los resultados de las evaluaciones. Los stakeholder pueden participar en las comisiones de evaluación o en un grupo asesor.

La evaluación no puede sustituir a un debate público informado, si bien puede aportar a éste. Tampoco puede sustituir las decisiones políticas o administrativas que deban tomarse, pero sí ubicarlas en un plano de discusión más racional.

Se ha llamado evaluación interactiva al proceso de investigación participativa que analiza la organización, el funcionamiento y desarrollo de un programa en relación con sus objetivos, las expectativas de sus participantes y los resultados obtenidos. Ella está basada en la interacción directa o indirecta de los usuarios del programa, de éstos con los técnicos y de los técnicos con los directivos.

En los servicios públicos resulta muy conveniente la definición de estándares de servicio, los que pueden incluir una descripción del servicio y/o los beneficios que los usuarios deben recibir, descripción de la calidad que puede esperarse en la entrega del servicio, objetivos específicos relativos a los principales aspectos de la prestación, el costo del servicio, y mecanismos que pueden utilizar los usuarios cuando sienten que no se han respetado los estándares correspondientes. Estos estándares de servicio pueden ser diseñados de modo más preciso en relación a los diversos grupos de usuarios o de finalidades./ 
Para medir la satisfacción de los usuarios de servicios públicos pueden utilizarse indicadores diversos, incluyendo aquellos referidos a las instalaciones físicas del servicio, la facilidad de comunicación y comprensibilidad de lo solicitado, el trato y la actitud del personal, la calidad de los servicios recibidos, y una apreciación de conjunto hecha por el usuario.

Desde otro punto de vista, los usuarios deberían ser consultados rutinariamente sobre la calidad de la gestión pública y sus resultados. 


\section{Conclusiones}

Los sistemas políticos difieren, sea superficial o profundamente. De allí que la política y las políticas públicas pueden no encontrarse, hacerlo parcialmente o de modo esporádico; esto es un hecho.

La búsqueda de la política y las políticas públicas representa una modernización de la esfera pública; este es un juicio.

Tal mejora requiere cambios en el sistema político y en el gobierno:

- los partidos, los grupos sociales y las personas requieren interiorizar el análisis de los institutos de políticas públicas, sea que estén en el gobierno o en la oposición y

- la reforma del estado debe hacerse en torno a decisiones de políticas públicas. Primero la función, después el organigrama y sólo hasta que cambie la función; un gobierno con entradas y salidas. 



\section{Bibliografía}

Arrow, Kenneth (1951), Social Choices and Individual Values, Wiley, New York.

Banco Interamericano de Desarrollo (1998), "El proceso de decisiones fiscales democráticas al nivel nacional, en América Latina tras una década de reformas", Washington D.C.

Beam, David (1996), "If Public Ideas are so Important Now, Why are Policy Analysis so Depressed?" Journal of Policy Analysis and Management, Volumen 15, $\mathrm{N}^{\mathrm{o}} 3$.

Bhatnagar, Bhuven y A. Williams (1993), "Introduction", World Bank Discussion Papers $N^{o}$ 183, Washington D.C., Banco Mundial.

, (1992), "Participatory Development and the World Bank: Potential Directions for Change", World Bank Discussion Papers, $\mathrm{N}^{\mathrm{o}}$ 183, Washington D.C. Banco Mundial.

Boeninger, Edgardo (1993), "Coordinación y coherencia en la acción del gobierno. Algunas propuestas a partir de la experiencia", Documento interno, Secretaría General de la Presidencia, Santiago de Chile, noviembre.

Briones, Guillermo, "La evaluación interactiva", Santiago de Chile, Programa Interdisciplinario de Investigaciones en Educación (PIIE), (s/f).

Buchanan, J.M. (1968), "An Economist's Approach to Scientific Politics", en M. Parsons, (ed), Perspective in the Study of Politics, Rand Mc Nally, Chicago.

CEPAL (1996), "Descentralización fiscal en América Latina", Notas sobre la economía y el desarrollo $N^{\circ} 596$, Santiago de Chile, octubre.

Cohen, Daniel (2002), "La fin du conflict droite-gauche", Le Monde, abril.

Cohen, Michael, James March y Johan Olsen, (1972), "A Garbage Can Model of Organizational Choice", Administrative Science Quarterly 17, March.

Deutsch, Karl (1966), The Nerves of Government, The Free Press, New York.

Downs, Anthony, (1972), "Up and Down with Ecology - The "Issue-Attention Cycle". The Public Interest 28. 
Frohmann, Alicia, (2203), "Consultas con la sociedad civil sobre negociaciones comerciales: el caso de Chile, Ponencia en Seminario, BID, Milán.

Gobierno de Nueva Zelandia (1992), “The Policy Advice Initiative: Opportunities for Management”, State Service Commission.

Heclo, Hugo, (2000), "Campaigning and Governing: a Conspectus", en Norman Omstein y Thomas Mann, editors, The Permanent Campaign and its Future, Washington, American Enterprice Institute - The Brookings Institution.

Jenkins-Smith, Hank y P.A. Sabatier (1993), “The Study of the Public Policy Process”, en Paul A. Sabatier y Hank C. Jenkins-Smith (eds) Policy Change and Learning: An Advocacy Coalition Approach, Boulder, CO, Westview Press.

Johnson, Erik, (1966) “Cómo funcionan los institutos de políticas”, Reforma Económica $\mathrm{N}^{\mathrm{O}}$ 3, Revista editada por el CIPE, de Washington D.C.

Kaufmann, Herbert, (1976), “Are Governmental Organizations Inmortal?“, Brooking Institution, Washington D.C.

Kingdom, John, (1995), Agendas, Alternatives, and Public Policies, Harper Collins, New York.

Lahera, Eugenio, (2003), Intrdoducción a las políticas públicas, Colección Brevarios No 538, Fonde de Cultura Económica.

, (1192), "Un sector público con entrada y salida", El Diario, Santiago de Chile,29 de mayo.

Lahera, Eugenio y Mabel Cabezas (2000), "Governance and Institutional Development of the Chilean Economy, Journal of International Development 12.

Majone, Ginadomenico, (1997), Evidencia, argumentación y persuación en la formulación de políticas, México, Fondo de Cultura Económica.

Medellín, Pedro, (2003), "La política en los procesos de estructuración de las políticas públicas en Colombia, documento de trabajo, Bogotá.

Ministério de Administraçao Federal e Reforma do Estado (MARE), (1988), “Organizaçoes Sociais”,Brasilia.

Nelson, Robert, (1987), "The Economics Profession and the Making of Public Policy", Journal of Economic Literature, Volumen 25, March.

Nonell, Rosa, (1987), "Estructuras de concertación económica: una aproximación metodológica conceptual”, Cuadernos de Economía vol. 15, N ${ }^{\circ}$ 45, Barcelona, mayo/agosto.

Olson, Mancurs, (1965), The Logic of Collective Action, Cambridge, Mass. Harvard University Press.

Organización para la Cooperación y Desarrollo Económico (OCDE), (1996), Builing Policy Coherence. Tools and Tensions", Public Management Ocassional Papers $\mathrm{N}^{\mathrm{O}} 12$, Paris.

Paul ,Samuel, (1994), “Does Voice Matter? For Public Accountability, Yes”, Policy Research Working Paper $\mathrm{N}^{\mathrm{o}}$ 1388, Washington, D.C., Banco Mundial, diciembre.

Pizarro, Eduardo, (1995), La comisión para la reforma de los partidos”, Análsis político $N^{o}$ 26, Santa Fé de Bogotá, septiembre/diciembre.

Rawls, John, (1971), A Theory of Justice. Traducido al español por el FCE, en 1979; la 3ra. Edición es del año 2000, y Rawls John (2000), Collected Papers Harvard.

Rodríguez, Angela, (2003), "De la ficha CAS al Programa Chile Solidario", Tesis de pre-grado, Universidad de Los Lagos, Santiago.

Saint Paul, Guilles, (2000), “The New Political Economy: Recent Books by Allen Drazen and by Torsten Persson and Guido Tabellini”, Journal of Economic Literature vol. XXXVIII, December.

Schick, Allen, (1998), Why Most Developing Countries Should not try New Zeland's Reforms", The World Bank Research Observer, vol. 13, $\mathrm{N}^{\mathrm{o}}$ 1, February.

Sen, Amartya, (1998), "The Possibility of SocialChoice”, The American Economic Review, vol. 89, No 3.

Tironi, Luis F., (1993), Para el caso de Estados Unidos veáse (1995), "Putting customers first '95. Standards for Serving the American People", National Performance Review, Washington, D.C. October.

Treasury Board of Canada, (1995), Quality Services, Measuring Client Satisfaction, Ottawa, October.

Winkler, Donald, (1994), The Design and Administration of Intergovernmental Transfers.Fiscal Decentralizaciton in Latin America", World Bank Discussion Papers $\mathrm{N}^{\mathrm{0}} 235$, Washington, D.C. Banco Mundial, julio. 


\section{E P A L políticas sociales}

\section{Números publicados}

1. Andrés Necochea, La postcrisis: ¿una coyuntura favorable para la vivienda de los pobres? (LC/L.777), septiembre de 1993.

2. Ignacio Irarrázaval, El impacto redistributivo del gasto social: una revisión metodológica de estudios latinoamericanos (LC/L.812), enero de 1994.

3. Cristián Cox, Las políticas de los noventa para el sistema escolar (LC/L.815), febrero de 1994.

4. Aldo Solari, La desigualdad educativa: problemas y políticas (LC/L.851), agosto de 1994.

5. Ernesto Miranda, Cobertura, eficiencia y equidad en el área de salud en América Latina (LC/L.864), octubre de 1994.

6. Gastón Labadie y otros, Instituciones de asistencia médica colectiva en el Uruguay: regulación y desempeño (LC/L.867), diciembre de 1994.

7. María Herminia Tavares, Federalismo y políticas sociales (LC/L.898), mayo de 1995.

8. Ernesto Schiefelbein y otros, Calidad y equidad de la educación media en Chile: rezagos estructurales y criterios emergentes (LC/L.923), noviembre de 1995.

9. Pascual Gerstenfeld y otros, Variables extrapedagógicas y equidad en la educación media: hogar, subjetividad y cultura escolar (LC/L.924), diciembre de 1995.

10. John Durston y otros, Educación secundaria y oportunidades de empleo e ingreso en Chile (LC/L.925), diciembre de 1995.

11. Rolando Franco y otros, Viabilidad económica e institucional de la reforma educativa en Chile (LC/L.926), diciembre de 1995.

12. Jorge Katz y Ernesto Miranda, Reforma del sector salud, satisfacción del consumidor y contención de costos (LC/L.927), diciembre de 1995.

13. Ana Sojo, Reformas en la gestión de la salud pública en Chile (LC/L.933), marzo de 1996.

14. Gert Rosenthal y otros, Aspectos sociales de la integración, Volumen I, (LC/L.996), noviembre de 1996. Eduardo Bascuñán y otros, Aspectos sociales de la integración, Volumen II, (LC/L.996/Add.1), diciembre de 1996. Secretaría Permanente del Sistema Económico Latinoamericano (SELA) y Santiago González Cravino, Aspectos sociales de la integración, Volumen III, (LC/L.996/Add.2), diciembre de 1997.

Armando Di Filippo y otros, Aspectos sociales de la integración, Volumen IV, (LC/L.996/Add.3), diciembre de 1997.

15. Iván Jaramillo y otros, Las reformas sociales en acción: salud (LC/L.997), noviembre de 1996.

16. Amalia Anaya y otros, Las reformas sociales en acción: educación (LC/L.1000), diciembre de 1996.

17. Luis Maira y Sergio Molina, Las reformas sociales en acción: Experiencias ministeriales (LC/L.1025), mayo de 1997.

18. Gustavo Demarco y otros, Las reformas sociales en acción: Seguridad social (LC/L.1054), agosto de 1997.

19. Francisco León y otros, Las reformas sociales en acción: Empleo (LC/L.1056), agosto de 1997.

20. Alberto Etchegaray y otros, Las reformas sociales en acción: Vivienda (LC/L.1057), septiembre de 1997.

21. Irma Arriagada, Políticas sociales, familia y trabajo en la América Latina de fin de siglo (LC/L.1058), septiembre de 1997.

22. Arturo León, Las encuestas de hogares como fuentes de información para el análisis de la educación y sus vínculos con el bienestar y la equidad (LC/L.1111), mayo de 1998. wmw

23. Rolando Franco y otros, Social Policies and Socioeconomic Indicators for Transitional Economies (LC/L.1112), mayo de 1998.

24. Roberto Martínez Nogueira, Los proyectos sociales: de la certeza omnipotente al comportamiento estratégico (LC/L.1113), mayo de 1998. www

25. Gestión de Programas Sociales en América Latina, Volumen I (LC/L.1114), mayo de 1998. www Metodología para el análisis de la gestión de Programas Sociales, Volumen II (LC/L.1114/Add.1), mayo de 1998. www

26. Rolando Franco y otros, Las reformas sociales en acción: La perspectiva macro (LC/L.1118), junio de 1998. www

27. Ana Sojo, Hacia unas nuevas reglas del juego: Los compromisos de gestión en salud de Costa Rica desde una perspectiva comparativa (LC/L.1135), julio de 1998. mww

28. John Durston, Juventud y desarrollo rural: Marco conceptual y contextual (LC/L.1146), octubre de 1998. www

29. Carlos Reyna y Eduardo Toche, La inseguridad en el Perú (LC/L.1176), marzo de 1999. www

30. John Durston, Construyendo capital social comunitario. Una experiencia de empoderamiento rural en Guatemala (LC/L.1177), marzo de 1999. wmw

31. Marcela Weintraub y otras, Reforma sectorial y mercado de trabajo. El caso de las enfermeras en Santiago de Chile (LC/L.1190), abril de 1999.

32. Irma Arriagada y Lorena Godoy, Seguridad ciudadana y violencia en América Latina: Diagnóstico y políticas en los años noventa (LC/L.1179-P), Número de venta: S.99.II.G.24 (US\$10.00), agosto de 1999. www 
33. CEPAL PNUD BID FLACSO, América Latina y las crisis (LC/L.1239-P), Número de venta: S.00.II.G.03 (US\$10.00), diciembre de 1999. www

34. Martín Hopenhayn y otros, Criterios básicos para una política de prevención y control de drogas en Chile (LC/L.1247-P), Número de venta: S.99.II.G.49 (US\$ 10.00), noviembre de 1999. www

35. Arturo León, Desempeño macroeconómico y su impacto en la pobreza: análisis de algunos escenarios en el caso de Honduras (LC/L.1248-P), Número de venta S.00.II.G.27 (US\$10.00), enero de 2000. www

36. Carmelo Mesa-Lago, Desarrollo social, reforma del Estado y de la seguridad social, al umbral del siglo XXI (LC/L.1249-P), Número de venta: S.00.II.G.5 (US\$ 10.00), enero de 2000. www

37. Francisco León y otros, Modernización y comercio exterior de los servicios de salud/Modernization and Foreign Trade in the Health Services (LC/L.1250-P) Número de venta S.00.II.G.40/E.00.II.G.40 (US\$10.00), marzo de 2000. www

38. John Durston, ¿Qué es el capital social comunitario? (LC/L.1400-P), Número de venta S.00.II.G.38 (US\$ 10.00), julio de 2000. wmw

39. Ana Sojo, Reformas de gestión en salud en América Latina: los cuasimercados de Colombia, Argentina, Chile y Costa Rica (LC/L.1403-P), Número de venta S.00.II.G.69 (US\$10.00), julio de 2000. www

40. Domingo M. Rivarola, La reforma educativa en el Paraguay (LC/L.1423-P), Número de venta S.00.II.G.96 (US\$ 10.00), septiembre de 2000. www

41. Irma Arriagada y Martín Hopenhayn, Producción, tráfico y consumo de drogas en América Latina (LC/L.1431-P), Número de venta S.00.II.G.105 (US\$10.00), octubre de 2000. wmw

42. ¿Hacia dónde va el gasto público en educación? Logros y desafíos, 4 volúmenes:Volumen I: Ernesto Cohen y otros, La búsqueda de la eficiencia (LC/L.1432-P), Número de venta S.00.II.106 (US\$10.00), octubre de 2000. www

Volumen II: Sergio Martinic y otros, Reformas sectoriales y grupos de interés (LC/L.1432/Add.1-P), Número de venta S.00.II.G.110 (US\$10.00), noviembre de 2000. www

Volumen III: Antonio Sancho y otros, Una mirada comparativa (LC/L.1432/Add.2-P), Número de venta S.01.II.G.4 (US\$10.00), febrero de 2001. wmw

Volumen IV: Silvia Montoya y otros, Una mirada comparativa: Argentina y Brasil (LC/L.1432/Add.3-P), Número de venta S.01.II.G.25 (US\$10.00), marzo de 2001. www

43. Lucía Dammert, Violencia criminal y seguridad pública en América Latina: la situación en Argentina (LC/L.1439-P), Número de venta S.00.II.G-125 (US\$10.00), noviembre de 2000. www

44. Eduardo López Regonesi, Reflexiones acerca de la seguridad ciudadana en Chile: visiones y propuestas para el diseño de una política (LC/L.1451-P), Número de venta S.00.II.G.126 (US\$10.00), noviembre 2000. www

45. Ernesto Cohen y otros, Los desafíos de la reforma del Estado en los programas sociales: tres estudios de caso (LC/L.1469-P), Número de venta S.01.II.G.26 (US\$10.00), enero de 2001. www

46. Ernesto Cohen y otros, Gestión de programas sociales en América Latina: análisis de casos, 5 volúmenes: Volumen I: Proyecto Joven de Argentina (LC/L.1470-P), Número de venta S.01.II.G.5 (US\$10.00), enero de 2001. wwww Volumen II: El Programa Nacional de Enfermedades Sexualmente Transmisibles (DST) y Síndrome de Inmunodeficiencia Adquirida (SIDA) de Brasil (LC/L.1470/Add.1-P), Número de venta S.01.II.G.5 (US\$10.00), enero de 2001. wmw Volumen III: El Programa de Restaurantes Escolares Comunitarios de Medellín, Colombia (LC/L.1470/Add.2-P), Número de venta S.01.II.G.5 (US\$10.00), enero de 2001. www

Volumen IV: El Programa Nacional de Apoyo a la Microempresa de Chile (LC/L.1470/Add.3-P), Número de venta S.01.II.G.5 (US\$10.00), enero de 2001. www

Volumen V: El Programa de Inversión Social en Paraguay (LC/L.1470/Add.3-P), Número de venta S.01.II.G.5 (US\$10.00), enero de 2001. wmw

47. Martín Hopenhayn y Alvaro Bello, Discriminación étnico-racial y xenofobia en América Latina y el Caribe.(LC/L.1546), Número de venta S.01.II.G.87 (US\$10.00), mayo de 2001. www

48. Francisco Pilotti, Globalización y Convención sobre los Derechos del Niño: el contexto del texto (LC/L.1522-P), Número de venta S.01.II.G.65 (US\$ 10.00), marzo de 2001. www

49. John Durston, Capacitación microempresarial de jóvenes rurales indígenas en Chile (LC/L. 1566-P), Número de venta S.01.II.G.112 (US\$10.00), julio de 2001. www

50. Agustín Escobar Latapí, Nuevos modelos económicos: ¿nuevos sistemas de movilidad social? (LC/L.1574-P), Número de venta S.01.II.G.117 (US\$ 10.00), julio de 2001. wmw

51. Carlos Filgueira, La actualidad de viejas temáticas: sobre los estudios de clase, estratificación y movilidad social en América Latina (LC/L 1582-P), Número de venta S.01.II.G.125 (US\$ 10.00), julio de 2001. www

52. Arturo León, Javier Martínez B., La estratificiación social chilena hacia fines del siglo XX (LC/L.1584-P), Número de venta S.01.II.G.127 (US\$ 10.00), agosto de 2001. wmw

53. Ibán de Rementería, Prevenir en drogas: paradigmas, conceptos y criterios de intervención (LC/L. 1596-P), Número de venta S.01.II.G.137 (US\$ 10.00), septiembre de 2001. www

54. Carmen Artigas, El aporte de las Naciones Unidas a la globalización de la ética. Revisión de algunas oportunidades. (LC/L. 1597-P), Número de venta: S.01.II.G.138 (US\$ 10.00), septiembre de 2001. www 
55. John Durston, Capital social y políticas públicas en Chile. Investigaciones recientes. Volumen I, (LC/L. 1606-P), Número de venta: S.01.II.G.147 (US\$ 10.00), octubre de 2001 y Volumen II, (LC/L.1606/Add.1-P), Número de venta: S.01.II.G.148 (US\$ 10.00), octubre de 2001. wmw

56. Manuel Antonio Garretón, Cambios sociales, actores y acción colectiva en América Latina. (LC/L. 1608-P), Número de venta: S.01.II.G.150 (US\$10.00), octubre de 2001. www

57. Irma Arriagada, Familias latinoamericanas. Diagnóstico y políticas públicas en los inicios del nuevo siglo. (LC/L. 1652-P), Número de venta: S.01.II.G.189 (US\$ 10.00), diciembre de 2001 www

58. John Durston y Francisca Miranda, Experiencias y metodología de la investigación participativa. (LC/L.1715-P), Número de venta: S.02.IIG.26 (US\$10.00), marzo de 2002. www

59. Manuel Mora y Araujo, La estructura social argentina. Evidencias y conjeturas acerca de la estratificación social, (LC/L 1772-P), Número de venta: S.02.IIG.85 (US\$ 10.00), septiembre de 2002. www

60. Lena Lavinas y Francisco León, Emprego feminino no Brasil: mudanças institucionais e novas inserções no mercado de trabalho, Volumen I (LC/L.1776-P), Número de venta S.02.IIG.90 (US\$ 10.00), agosto de 2002 y Volumen II, (LC/L.1776/Add.1-P) Número de venta S.02.IIG.91 (US\$10.00), septiembre de 2002. www

61. Martín Hopenhayn, Prevenir en drogas: enfoques integrales y contextos culturales para alimentar buenas prácticas, (LC/L.1789-P), Número de venta: S.02.II.G.103 (US\$ 10.00), octubre de 2002. www

62. Fabián Repetto, Autoridad Social en Argentina. Aspectos político-institucionales que dificultan su construcción. (LC/L.1853-P), Número de venta: S.03.II.G.21, (US\$ 10.00), febrero de 2003. www

63. Daniel Duhart y John Durston, Formación y pérdida de capital social comunitario mapuche. Cultura, clientelismo y empoderamiento en dos comunidades, 1999-2002. (LC/1858-P), Número de venta: S.03.II.G.30, (US\$ 10.00),febrero de 2003. www

64. Vilmar E. Farias, Reformas institucionales y coordinación gubernamental en la política de protección social de Brasil, (LC/L.1869-P), Número de venta: S.03.II.G.38, (US\$ 10.00), marzo de 2003. www

65. Ernesto Araníbar Quiroga, Creación, desempeño y eliminación del Ministerio de Desarrollo Humano en Bolivia, (LC/L.1894-P), Número de venta: S.03.II.G.54, (US\$10.00), mayo de 2003. wmw

66. Gabriel Kessler y Vicente Espinoza, Movilidad social y trayectorias ocupacionales en Argentina: rupturas y algunas paradojas del caso de Buenos Aires, LC/L. 1895-P), Número de venta: S.03.II.G.55, (US\$ 10.00), mayo de 2003. . www

67. Francisca Miranda y Evelyn Mozó, Capital social, estrategias individuales y colectivas: el impacto de programas públicos en tres comunidades campesinas de Chile, (LC/L.1896-P), Número de venta: S.03.II.G.53, (US\$ 10.00), mayo de 2003 . www

68. Alejandro Portes y Kelly Hoffman, Las estructuras de clase en América Latina: composición y cambios durante la época neoliberal, (LC/L.1902-P), Número de venta: S.03.II.G.61, (US\$ 10.00), mayo de 2003. www

69. José Bengoa, Relaciones y arreglos políticos y jurídicos entre los estados y los pueblos indígenas en América Latina en la última década, (LC/L.1925-P), Número de venta: S.03.II.G.82, (US\$ 10.00), agosto de 2003. www

70. Sara Gordon R., Ciudadanía y derechos sociales. ¿Criterios distributivos?, (LC/L.1932-P), Número de venta: S.03.II.G.91, (US\$ 10.00),julio de 2003. www

71. Sergio Molina, Autoridad social en Chile: un aporte al debate (LC/L.1970-P), Número de venta: S.03.II.G.126, (US\$ 10.00), septiembre de 2003. www

72. Carmen Artigas, "La incorporación del concepto de derechos económicos sociales y culturales al trabajo de la CEPAL", (LC/L.1964-P), Número de venta S.03.II.G.123, (US\$ 10.00), septiembre de 2003. www

73. José Luis Sáez, "Economía y democracia. Los casos de Chile y México", (LC/L-1978-P), Número de venta: S.03.II.G.137, (US\$ 10.00), septiembre de 2003. www

74. Irma Arriagada y Francisca Miranda (compiladoras), "Capital social de los y las jóvenes. Propuestas para programas y proyectos”, Volúmen I. LC/L.1988-P), Número de venta: S.03.II.G.149, (US\$ 10.00), septiembre de 2003. www Volúmen II. LC/L.1988/Add.1-P), Número de venta: S.03.II.G.150, (US\$ 10.00), septiembre de 2003. wmw

75 Luz Marina Quiroga, Pablo Villatoro, "Tecnologías de información y comunicaciones: su impacto en la política de drogas en Chile”. Extracto del informe final CEPAL, CONACE”, (LC/L.1989-P), Número de venta: S.03.II.G.151, (US\$ 10.00), noviembre de 2003. www

76 Rodrigo Valenzuela Fernández, Inequidad, ciudadanía y pueblos indígenas en Chile, (LC/L.2006-P), Número de venta: S.03.II.G.167, (US\$10.00), noviembre de 2003. www

77 Sary Montero y Manuel Barahona, "La estrategia de lucha contra la pobreza en Costa Rica. InstitucionalidadFinanciamiento- Políticas- Programas, (LC/L.2009-P), Número de venta: S.03.II.G.170, (US\$ 10.00), noviembre de 2003. www

78 Sandra Piszk y Manuel Barahona, Aproximaciones y desencuentros enla configuración de una autoridad social en Costa Rica: relato e interpretación de una reforma inconclusa, (LC/L.2027-P), Número de venta: S.03.II.G.191, (US\$ 10.00), diciembre de 2003. www

79 Ernesto Cohen, Rodrigo Martínez, Pedro Donoso y Freddy Aguirre, "Localización de infraestructura educativa para localidades urbanas de la Provincia de Buenos Aires”, (LC/L.2032-P), Número de venta: S.03.II.G.194, (US\$ 10.00), diciembre de 2003. www 
80 Juan Pablo Pérez Saínz, Katherine Andrade-Eekhoff, Santiago Bustos y Michael Herradora, "El orden social ante la globalización: Procesos estratificadores en Centroamérica durante la década de los noventa”, (LC/L.2037-P), Número de venta: S.03.II.G.203, (US\$10.00), diciembre de 2003. www

81 Carmen Artigas, "La reducción de la oferta de drogas. Introducción a algunos intrumentos internacionales", LC/L.2044-P), Número de venta: S.03.II.G.207, (US\$ 10.00), diciembre de 2003 www

82 Roberto Borges Martins, "Desigualdades raciais et políticas de inclusão racial: um sumário da experiência brasileira recente", (LC/L.2082-P), Número de venta: S.04.II.G.22, (US\$ 10.00), abril de 2004 www Roberto Borges Martins, "Desigualdades raciales y políticas de inclusión racial; resumen de la experiencia brasileña reciente", (LC/L.2082-P), Número de venta: S.04.II.G.22, (US\$ 10.00), marzo de 2004.. www

83 Rodrigo Valenzuela Fernández, "Inequidad y pueblos indígenas en Bolivia. (LC/L. 2089-P), Número de venta: S.04.II.G.27, (US\$ 10.00), marzo de 2004. wmw

84 Laura Golbert, “¿Derecho a la inclusión o paz social ? El Programa para Jefes/as de Hogares Desocupados”. (LC/L. 2092-P), Número de venta: S.04.II.G.30, (US\$ 10.00), abril de 2004. wmw

85 Pablo Vinocur y Leopoldo Halperini, "Pobreza y políticas sociales en Argentina de los años noventa" (LC/L.2107-P), Número de venta: S.04.II.G.59, (US\$ 10.00), abril de 2004. www

86 Alfredo Sarmiento Gómez, "La institucionalidad social en Colombia: la búsqueda de una descentralización con centro", (LC/L. 2122-P), Número de venta: S.04.II.G.51, (US\$10.00), mayo de 2004. www

87 Pablo Villatoro, "Los programas de reducción de la pobreza en América Latina. Un análisis de cinco experiencias." (LC/L.2133-P), Número de venta: S.04.II.G.62, (US\$10.00), mayo de 2004. www

88 Arturo Léon, Rodrigo Martínez, Ernesto Espíndola y Alejandro Schejtman, "Pobreza, hambre y seguridad alimentaria en Centroamérica y Panamá”, (LC/L.2134-P), Número de venta: S.04.II.G.63, (US\$10.00), mayo de 2004. www

89 Nelson do Valle Silva, "Cambios sociales y estratificación en el Brasil contemporáneo (1945-1999)" (LC/L.2163-P), Número de venta: S.04.II.G.91, (US\$10.00), julio de 2004. www

90 Gisela Zaremberg, "Alpargatas y libros: un análisis comparado de los estilos de gestión social del Consejo Provincial de la Mujer (Provincia de Buenos Aires, Argentina) y el Servicio Nacional de la Mujer (Chile)", (LC/L.2164-P), Número de venta: S.04.II.G.92, (US\$10.00), julio de 2004. www

91 Jorge Lanzaro, "La reforma educativa en Uruguay (1995-2000): virtudes y problemas de una iniciativa heterodoxa", (LC/L.2166-P), Número de venta: S.04.II.G.95, (US\$ 10.00), julio de 2004. www

92 Carlos Barba Solano, "Régimen de bienestar y reforma social en México", (LC/L.2168-P), Número de venta: S.04.II.G.97, (US\$ 10.00), julio de 2004. mww

93 Pedro Medellín Torres, "La política de las políticas públicas: propuesta teórica y metodológica para el estudio de las polítcas públicas en países de frágil institutionacionalidad”, (LC/L.2170-P), Número de venta: S.04.II.G.99, (US\$ 10.00), julio de 2004. www

94 Carlos Sojo, "Líneas de tensión: gestión política de la reforma económica. El Instituto Costarricense de Electricidad, ICE y la privatización de empresas públicas", (LC/L.2173-P), Número de venta: S.04.II.G101, (US\$ 10.00), julio de 2004. www

95 Eugenio Lahera P., "Política y políticas públicas", (LC/L.2176-P), Número de venta: S.04.II.G103, (US\$ 10.00), agosto de 2004. wmw

- El lector interesado en adquirir números anteriores de esta serie puede solicitarlos dirigiendo su correspondencia a la Unidad de Distribución, CEPAL, Casilla 179-D, Santiago, Chile, Fax (562) 210 2069, correo electrónico: publications@eclac.cl.

Nombre:

Actividad:

Dirección:

Código postal, ciudad, país:

Tel.:

Fax:

E.mail: 